\title{
Motor-based interventions improve language outcomes in children with autism: a systematic review
}

\author{
Christina E. Odeh', Rebecca Martell², Sarah Griffin ${ }^{1}$, Erik R. Johnson ${ }^{3}$, Allison L. Gladfelter ${ }^{3}$ \\ ${ }^{1}$ Physical Therapy, School of Allied Health \& Communicative Disorders, Northern Illinois University, DeKalb, IL; ${ }^{2}$ School of Interdisciplinary Health \\ Professions, Northern Illinois University, DeKalb, IL; ${ }^{3}$ Speech-Language Pathology, School of Allied Health \& Communicative Disorders, Northern \\ Illinois University, DeKalb, IL, USA
}

Purpose: Children with autism spectrum disorder (ASD) show motor deficits in addition to the social communication and repetitive behaviors characteristic of the disorder. However, these deficits have traditionally been targeted independently during intervention. The primary purpose of this systematic review was to determine whether interventions with motor targets improved language or social communication outcomes in individuals with ASD.

Methods: Five databases were searched using the following terms:autis*, asper*, motor*, therap*, interven*, and treat*. After eliminating irrelevant and duplicate articles, 74 articles underwent full text review to determine whether they met the inclusionary/exclusionary criteria. The 15 included articles were then checked for inter-rater reliability and appraised for the quality of their research design, treatment fidelity, and interobserver agreement. Following the quality appraisals, 13 included articles were analyzed for final data extraction.

Results: Of the 13 included studies, 12 showed at least one increased language outcome, seven demonstrated at least one increased motor outcome, and one revealed no significant change in either language or motor outcomes.

Conclusions: Consistent with previous research, many of the children with ASD presented weaknesses in both motor and language skills. In most studies, the motor-based interventions led to an increase in language skills, indicating language and motor system interdependence. These findings also suggest that co-treatment between physical therapists and occupational therapists alongside speech-language pathologists may be warranted when working with children with ASD.

Keywords: Autism, Motor intervention, Language outcomes

\section{INTRODUCTION}

Autism Spectrum Disorder (ASD) is a neurodevelopmental disorder characterized by persisting impairments in social communication and interaction as well as restricted and repetitive behavior, interest, and activity patterns presenting in early development [1]. There is currently no motor-related diagnostic criteria other than repetitive, stereotypic movement patterns, such as rocking or hand flapping [1]. Motor abilities implicated in children with ASD vary significantly. The presence of motor involvement in children with ASD is widespread, with up to $79 \%$ of children with ASD presenting with

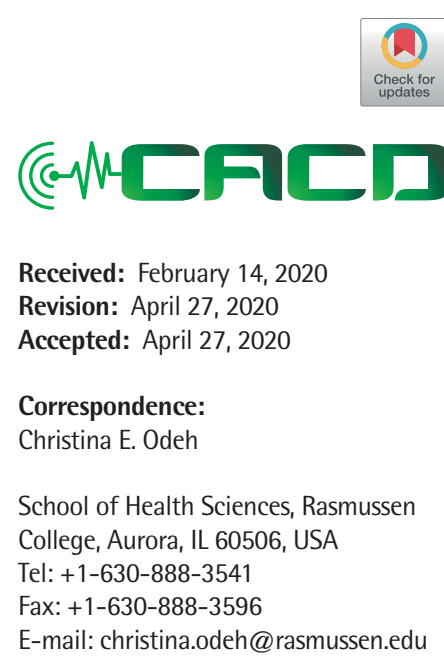

(C) 2020 The Korean Association of SpeechLanguage Pathologists

This is an Open Access article distributed under the terms of the Creative Commons Attribution NonCommercial License (https://creativecommons.org/ licenses/by-nc/4.0/) which permits unrestricted noncommercial use, distribution, and reproduction in any medium, provided the original work is properly cited. 
motor performance deficits [2]. Although motor impairments are known to present alongside communication weaknesses as a pervasive feature among children with ASD [3], motor and communication deficits traditionally are targeted independently of one-another. A shift from tradition toward a more integrative treatment approach may be warranted, as a growing body evidence suggests not only a relationship, but a level of interdependence between motor and language systems is present $[4,5]$.

A critical relationship between the developing motor and language systems in children with ASD has been made evident. The evidence of relationship between motor and language development is demonstrated in the multiple findings which illustrate that motor function during infancy and toddlerhood is predictive of later communicative skills in children with ASD [6-8]. Stone and Yoder [8] found that motor imitation skills during toddlerhood is predictive of later preschool-aged speech fluency in children with ASD. Poon and colleagues [7] observed that a delay in the development of imitation and object play skills is predictive of communication ability by age 3 . Furthermore, motor skill at 6 months of age was found to predict expressive language at 30 and 36 months of age in children with ASD [7]. LeBarton and Landa [6] even suggested that early inclusion of motor intervention may serve to mitigate the impact of motor delay on later social and communicative skills in children with ASD.

The intricacy of connection between developing motor and language systems is not fully understood; however, recent evidence has revealed that differences in ability between domains of motor learning may provide differing contribution and impact to communication and language development in children with ASD. Mody et al. [9] suggested a difference in influence of gross versus fine motor abilities on communication profiles in children with ASD. In their retrospective study, for children with ASD aged 2-17 years, it was found that as fine motor scores on the Mullen Scales of Early Learning (MSEL) increased, MSEL receptive and expressive language scores also increased. Similar findings were not present when gross motor abilities were examined; a lack of relationship between gross motor and expressive language as well as a negative relationship between gross motor and receptive language was found. The authors went on to speculate that impairment in gross motor functioning may affect the development of joint attention abilities, possibly accounting for a resultant difficulty attending to speech impacting receptive language development.

Despite the need for a more complete understanding of the breadth and intricacy of the relationship between motor and language development in children with ASD, it is evident that a complex relationship exists. The presence of interactivity between motor and language systems necessitates consideration for both systems in approach to diagnosis and treatment. There is an emerging body of evidence indicating a relationship and degree of interactivity between developing motor and language systems in both neurotypical children and children with ASD [10]. This implicates the need for further investigation to determine whether incorporation of intervention targeting motor function influences outcomes in language and social functioning for individuals with ASD. The primary objective of this systematic review was to determine whether interventions targeting motor function facilitate improvement in language outcomes in individuals with ASD.

\section{METHODS}

\section{Inclusion criteria}

In order to be included in this review, the participants had to meet the following criteria: 1) presented with Autism Spectrum Disorder, PDD-NOS, or Asperger's Syndrome according to the DSM-IV or V, the International Classification of Diseases, the Autism Diagnostic Observation Schedule or the Autism Diagnostic Interview-Revised, 2) had not begun or altered a pharmacological intervention within three months of the onset of the experiment, 3) did not present a concomitant diagnosis of a genetic, cognitive, or hearing impairment (e.g., Fragile-X, Angleman, etc.) at the start of treatment, and 4) were not labeled as bilingual learners of language. The studies reviewed had to also meet the following criteria: 1) reported outcomes for at least one language-based measurement, 2) included a treatment or intervention; the study may have evaluated one treatment or compared two or more treatments, 3) focused on a motor-based treatment, 4) did not use graphic symbols as a sole means of communication (such as early phases of Picture Exchange Communication System), 5) employed a (quasi-) experimental design for evaluating the effectiveness or efficiency of a treatment, such as selected (quasi-) experimental group designs or single-subject experimental designs (pre-experimental designs such as AB-designs or group equivalents were excluded), 6) was written as an article in a refereed journal, a book chapter, or a document made available through the ERIC; or it appeared in published conference proceedings or as an unpublished Master's thesis or doctoral dissertation, and 7) the experiment was dated be- 
tween 1989 and December 2019 (including those that are published on-line first).

\section{Search strategy}

The following electronic databases were searched: CINAHL, Web of Science, PsycINFO, Cochrane. The following key words were used when searching for articles: autis*, asper*, motor*, therap*, interven*, and treat*. Using these search terms, the initial title hits resulted in 5,584 articles. Then, abstracts were assessed to further compare appropriateness of inclusionary/exclusionary criteria. Following the abstract review and after eliminating duplicate articles, 74 articles underwent full text review to determine whether they met the inclusionary/exclusionary criteria.

Full-text review was completed by an undergraduate student majoring in pre-physical therapy and a speech-language pathology master's student. All 74 articles underwent an inclusion/exclusion criteria process, in which the study had to meet all 11 check points on the inclusion checklist to be included in the systematic review. Following the full-text review, 15 articles remained in the systematic review.

\section{Interrater reliability for inclusion criteria}

Coding on 37 (roughly 50\%) of the 74 articles was also applied, blindly, by a speech-language pathologist with a $\mathrm{PhD}$ to determine the interrater reliability of the application of the inclusion checklist during the full-text review. Interrater agreement before consensus building was $91 \%$, Kappa $=0.83$, Phi $=0.84$. Disagreements were resolved through a consensus process.

\section{Guidelines for study evaluation}

A study quality appraisal rating was completed on each study following the guidelines put forth by Simeonsson and Bailey [11]. This system classifies evidence into four categories: conclusive, preponderant, suggestive, and inconclusive. These categories are based on three types of information: research design, interrater reliability (IRR), and treatment fidelity (TF). A conclusive classification includes articles that have a clear, sound research design, adequate IRR and TF, and provide outcomes that undoubtedly resulted from the intervention implemented. A preponderant study showed minor flaws in either the research design or in the IRR or TF reported and presented outcomes that are likely to have occurred due to the intervention. Suggestive studies reported flawed or missing IRR or TF, some minor design flaws, and resulted in outcomes that could possibly be drawn from of the intervention.
Finally, an inconclusive study had either fatal design flaws or had missing IRR and TF and showed that no conclusion could be made about the outcomes of the intervention. The study quality appraisal ratings were completed by an undergraduate student majoring in pre-physical therapy. The quality appraisal rating for each included study is presented in Table 1.

\section{Interrater reliability for quality appraisal ratings}

Five (33\%) of the 15 included articles were then checked for inter-rater reliability of the appraised quality of their research design, treatment fidelity, and interobserver agreement by a blind, second coder with a $\mathrm{PhD}$ in speech-language pathology. The interrater agreement was $100 \%$.

\section{Data extraction}

Following the quality appraisals, 13 included articles were analyzed for final data extraction using an agreed upon coding manual. The two articles (of the original 15 included) that did not undergo coding were classified as inconclusive. The study characteristics coded included: author, year, goal of the study, participant age, participant gender, participant diagnosis, measures used to assess baseline, intervention design, treatment used, intervention provider, intervention outcomes, interobserver agreement, treatment fidelity, and effect size.

\section{Interrater reliability for data coding}

The first round of data coding was completed by an undergraduate student majoring in pre-physical therapy. For IRR, 4 articles ( $30 \%$ of total) were randomly selected to be coded by a graduate student studying physical therapy. The second coding was done blindly. The resulting IRR was greater than $80 \%$ for all four articles, with a range of $83 \%$ to $95 \%$, resulting in an average IRR of $87 \%$. Disagreements were resolved through a consensus process.

\section{RESULTS}

\section{Participant characteristics}

At least part of the participants in an included study must present a diagnosis of Autism Spectrum Disorder according to the DSM-IV, DSM-V, ADOS, or ADI-R. A total of 253 children between the ages of 22 months and 16 years of age participated in the studies included.

\section{Research design}

Five studies implemented lower quality randomized con- 
Table 1. Summary or studies that examined language outcomes with motor interventions

\begin{tabular}{|c|c|c|c|c|c|c|}
\hline Authors & $\begin{array}{l}\text { Parti- } \\
\text { cipants }\end{array}$ & Goal of intervention & $\begin{array}{l}\text { Type of intervention } \\
\text { received }\end{array}$ & Language outcomes & Motor outcomes & Appraisal \\
\hline Ingersoll (2012) & $\begin{array}{l}\text { M: } 24 \\
\text { F: } 3\end{array}$ & $\begin{array}{l}\text { Increase participants' } \\
\text { language output and motor } \\
\text { performance }\end{array}$ & $\begin{array}{l}\text { Reciprocal Imitation } \\
\text { Training (RIT) }\end{array}$ & $\begin{array}{l}\text { Increase in social responsivity } \\
\text { (joint attention) }\end{array}$ & $\begin{array}{l}\text { No improvements in motor } \\
\text { skills }\end{array}$ & Preponderant \\
\hline $\begin{array}{l}\text { Ingersoll and Schreibman } \\
\text { (2006) }\end{array}$ & $\begin{array}{l}\mathrm{M}: 3 \\
\mathrm{~F}: 2\end{array}$ & $\begin{array}{l}\text { Increase participants' } \\
\text { language output and motor } \\
\text { performance }\end{array}$ & $\begin{array}{l}\text { Reciprocal Imitation } \\
\text { Training (RIT) }\end{array}$ & $\begin{array}{l}\text { Increased joint attention, pretend } \\
\text { play, and language (spontaneous } \\
\text { and imitated) with therapist and } \\
\text { caregiver }\end{array}$ & $\begin{array}{l}\text { Increased motor imitation } \\
\text { and spontaneous object } \\
\text { imitation }\end{array}$ & Preponderant \\
\hline $\begin{array}{l}\text { Ketcheson, Hauck, and } \\
\text { Ulrich (2017) }\end{array}$ & $\begin{array}{l}\text { M: } 15 \\
\text { F: } 5\end{array}$ & $\begin{array}{l}\text { Increase participants' } \\
\text { language output, } \\
\text { socialization, and motor } \\
\text { performance }\end{array}$ & $\begin{array}{l}\text { Classroom Pivotal } \\
\text { Response Training }\end{array}$ & $\begin{array}{l}\text { Decreased minutes in solitary time } \\
\text { (POPE), approached sig for } \\
\text { proximity and parallel aware. } \\
\text { No change in joint engagement, } \\
\text { parallel play and onlooking }\end{array}$ & $\begin{array}{l}\text { Increased locomotor, object } \\
\text { control and gross quotient } \\
\text { TGMD-2. No physical } \\
\text { activity differences }\end{array}$ & Preponderant \\
\hline $\begin{array}{l}\text { Schaaf, Benevides, } \\
\text { Mailloux, Faller, Hunt, } \\
\text { et al. (2014) }\end{array}$ & $\begin{array}{l}\text { M: } 17 \\
\text { F: } 15\end{array}$ & $\begin{array}{l}\text { Evaluate efficacy of OT/SI } \\
\text { following a manualized } \\
\text { protocol on individual goal } \\
\text { attainment }\end{array}$ & $\begin{array}{l}\text { Occupational therapy } \\
\text { using sensory } \\
\text { integration }\end{array}$ & $\begin{array}{l}\text { Decreased reliance on caregiver } \\
\text { assistance on social subscale of } \\
\text { the PEDI }\end{array}$ & $\begin{array}{l}\text { Decreased reliance on } \\
\text { caregiver assistance on } \\
\text { Self-care subscale of the } \\
\text { PEDI; no change in mobility } \\
\text { subscales }\end{array}$ & Preponderant \\
\hline $\begin{array}{l}\text { Borgi, Loliva, Cerino, } \\
\text { Chiarotti, Venerosi, } \\
\text { et al. (2016) }\end{array}$ & $\begin{array}{l}\text { M: } 28 \\
\text { F: } 0\end{array}$ & $\begin{array}{l}\text { Increase participants' } \\
\text { language output, motor } \\
\text { performance, planning, } \\
\text { problem solving and } \\
\text { socialization behavior }\end{array}$ & $\begin{array}{l}\text { Equine-assisted therapy } \\
\text { (EAT) }\end{array}$ & $\begin{array}{l}\text { VABS improved socialization } \\
\text { subscale; TOL planning time } \\
\text { (executive function) }\end{array}$ & $\begin{array}{l}\text { VABS improved motor } \\
\text { subscale }\end{array}$ & Suggestive \\
\hline $\begin{array}{l}\text { Caputo, Ippolito, } \\
\text { Mazzotta, Sentenza, } \\
\text { Muzio, et al. (2018) }\end{array}$ & $\begin{array}{l}\text { M: } 17 \\
\text { F: } 9\end{array}$ & $\begin{array}{l}\text { Increase participants' } \\
\text { language output and motor } \\
\text { performance }\end{array}$ & Aquatic therapy & $\begin{array}{l}\text { Increased on VABS Subscales of } \\
\text { Social Abilities; CARS - } \\
\text { emotional response, adaptation } \\
\text { to change, activity level }\end{array}$ & $\begin{array}{l}\text { Improved VABS - daily living } \\
\text { skills (as did control group); } \\
\text { Swimming skills increased, } \\
\text { but no control comparison } \\
\text { possible }\end{array}$ & Suggestive \\
\hline $\begin{array}{l}\text { Ingersoll and Lalonde } \\
\text { (2010) }\end{array}$ & $\begin{array}{l}\text { M: } 3 \\
\text { F: } 1\end{array}$ & $\begin{array}{l}\text { Increase participants' } \\
\text { language output and motor } \\
\text { performance }\end{array}$ & $\begin{array}{l}\text { Reciprocal Imitation } \\
\text { Training (RIT) }\end{array}$ & $\begin{array}{l}\text { Increase in number of word } \\
\text { combinations and spontaneous/ } \\
\text { flexible language }\end{array}$ & $\begin{array}{l}\text { No motor outcomes } \\
\text { measured }\end{array}$ & Suggestive \\
\hline Lau (2017) & $\begin{array}{l}\text { M: } 8 \\
\text { F: } 1\end{array}$ & Increase parent participation & $\begin{array}{l}\text { Transdisciplinary home- } \\
\text { based treatment }\end{array}$ & $\begin{array}{l}\text { No significant change on the } \\
\text { PEP-3 }\end{array}$ & $\begin{array}{l}\text { No significant change on the } \\
\text { PEP-3 }\end{array}$ & Suggestive \\
\hline $\begin{array}{l}\text { Miltenberger and Charlop } \\
\text { (2014) }\end{array}$ & $\begin{array}{l}\text { M: } 3 \\
\text { F: } 1\end{array}$ & $\begin{array}{l}\text { Increase participants' motor } \\
\text { performance }\end{array}$ & Athletic group games & $\begin{array}{l}\text { Increased number of single words } \\
\text { used communicatively, and } \\
\text { increased number of word } \\
\text { combination or sentences used } \\
\text { communicatively }\end{array}$ & $\begin{array}{l}\text { Improved gross motor } \\
\text { performance }\end{array}$ & Suggestive \\
\hline $\begin{array}{l}\text { Pfeiffer, Koenig, } \\
\text { Kinnealey, Sheppard, } \\
\text { Henderson (2011) }\end{array}$ & $\begin{array}{l}\text { M: } 32 \\
\text { F: } 5\end{array}$ & $\begin{array}{l}\text { Address sensory integration } \\
\text { intervention }\end{array}$ & $\begin{array}{l}\text { Sensory integration } \\
\text { therapy }\end{array}$ & Increase in social responsivity & $\begin{array}{l}\text { No changes in motor } \\
\text { performance; decrease in } \\
\text { atypical behaviors }\end{array}$ & Suggestive \\
\hline $\begin{array}{l}\text { Preis and McKenna } \\
\text { (2014) }\end{array}$ & $\begin{array}{l}\text { M: } 4 \\
\text { F: } 0\end{array}$ & $\begin{array}{l}\text { Increase in participants' } \\
\text { language output }\end{array}$ & $\begin{array}{l}\text { Sensory integration } \\
\text { therapy }\end{array}$ & $\begin{array}{l}\text { Increased number of single words } \\
\text { used communicatively, and } \\
\text { increases in spontaneous/ } \\
\text { flexible language }\end{array}$ & $\begin{array}{l}\text { No motor outcomes } \\
\text { measured }\end{array}$ & Suggestive \\
\hline Yoo and $\operatorname{Kim}(2018)$ & $\begin{array}{l}\text { M: } 33 \\
\text { F: } 19\end{array}$ & $\begin{array}{l}\text { Increase participants' } \\
\text { language output and motor } \\
\text { performance }\end{array}$ & Dyadic drum playing & $\begin{array}{l}\text { Increase in social skills on the } \\
\text { K-SSRS; increase in eye gaze } \\
\text { from pre- to post intervention; } \\
\text { no significant change in social } \\
\text { imitation skills }\end{array}$ & $\begin{array}{l}\text { Increased engaged joint } \\
\text { action; no significant } \\
\text { decrease in } \\
\text { asynchronization errors } \\
\text { during drum tapping }\end{array}$ & Suggestive \\
\hline $\begin{array}{l}\text { Zanobini and Solari } \\
\text { (2019) }\end{array}$ & $\begin{array}{l}\text { M:19 } \\
\mathrm{F}: 6\end{array}$ & $\begin{array}{l}\text { Increase in language, } \\
\text { decrease in stereotyped } \\
\text { behaviors }\end{array}$ & Aquatic Therapy & $\begin{array}{l}\text { Increased social responsivity on } \\
\text { SRS; Increased Social and Self- } \\
\text { Help Skills, Sensory, Body } \\
\text { Subscale of ABC; No significant } \\
\text { increases on Language and } \\
\text { Communication Subscale of ABC }\end{array}$ & $\begin{array}{l}\text { Swimming skills increased, } \\
\text { but no control comparison } \\
\text { possible }\end{array}$ & Suggestive \\
\hline
\end{tabular}

POPE, Playground Observation of Peer Engagement; TGMD-2, Test of Gross Motor Development, 2nd ed; PEDI, Pediatric Evaluation of Disability Inventory; VABS, Vineland Adaptive Behavior Scales; TOL, Tower of London; CARS, Childhood Autism Rating Scale; PEP-3, Psychoeducational Profile, 3rd ed; K-SSRS=Korean Social Skills Rating System; SRS =Social Responsiveness Scale; ABC, Autism Behavior Checklist. 
trolled trials [12-16]. This design compared randomly assigned participants using an experimental group and a control group and the coders were blinded from the purpose of the study. Three studies had observational studies with controls [17-19]. These studies compared two groups that were not randomly assigned using an experimental group and a control group. Three studies implemented an observational study [20-22]. These studies did not compare two groups but included single case studies that monitored TF and reported valid outcomes. Two studies had an observational study without controls design [23]. These studies compared two groups that were randomly assigned; however, they did not monitor TF or use reliable and valid outcome measures. One study implemented a strong single subject design [24]. This study used a single case experimental design that monitors TF and presents valid outcome measures. There was also one study that showed a high-quality randomized controlled trial [25]. This study randomly compared two groups, used blind coders, and monitored TF.

\section{Treatment fidelity}

Treatment fidelity (TF) means the overall consistency of the interventions at following their outlined procedure. TF is an important indicator of internal validity. Only one study reported TF [18]. Three of the studies took TF but only for $10 \%$ of the sessions that were completed $[13,24,25]$. One study took measurements for TF but did not report their findings [20].

\section{Interrater agreement}

Interrater agreement (IRR) is the percentage of agreement between two or more observers of the treatment intervention or treatment outcomes. An IRR of $80 \%$ or greater is acceptable and having independent and blind observers was needed for the highest possible ranking. IRR is used as an indicator of the reliability of the measurements, and because of this is also used for internal validity. There were only two articles that did not report IRR $[15,23]$. All thirteen articles that reported IRR reached at least $80 \%$ agreement.

\section{Quality study appraisal}

Fifteen studies met the inclusion criteria, the quality of the individual studies varied. No studies met the criteria to be classified as conclusive. Four studies $[13,18,24,25]$ were classified as preponderant. Nine included studies were ranked as suggestive [12,14,16,17,19-22,26]. The remaining two studies were classified as inconclusive $[15,23]$.

\section{Treatment effectiveness}

Of the 13 included studies, 12 reported increased language outcomes on at least one measure of language or social communication. Seven studies indicated an increased performance on at least one measure of motor skills. Only one included study revealed no significant change on any measure of language or motor skills.

\section{Language outcomes}

Twelve of the 13 studies reported increased language outcomes. These language outcomes ranged from increases in social responsivity (seven studies), the number of single words or word combinations produced (three studies), flexible language productions (two studies), joint attention or eye gaze (three studies), play skills (one study), appropriate emotional responses (one study), and general increases on broad scales of language (four studies). One study also reported decreases in solitary time. See Table 1 for individually reported article outcomes.

\section{Motor outcomes}

Only 11 of the 13 included studies collected motor outcome measures. Of these 11, seven reported increases on at least one motor outcome. These motor outcomes included increases in motor imitation skills (one study), object imitations or control (two studies), locomotor skills (one study), gross motor skills (two studies), engaged joint action (one study), swimming readiness (two studies), or increases on a broad measure of motor performance (one study).

\section{DISCUSSION}

The overarching aim of this systematic review was to determine whether motor-based interventions could lead to improved language outcomes in children with ASD. The results of this investigation were consistent with the increasing body of research that described a complex relationship between development in motor and communication skills in these children $[9,10,27]$. Although some of the specific language and motor results were mixed, 12 of the 13 included studies reported beneficial language outcomes in children with ASD who participated in motor-based interventions. Previously, motor function in infants and toddlers with ASD has been shown to be predictive of later communication skills [6-8]. The results of this systematic review hint at the possibility that this predictive relationship could be exploited as children 
with ASD continue to grow—-that targeting motor skills in isolation or alongside language could subsequently lead to improved language outcomes. As LeBarton and Landa [6] initially posited, the inclusion of motor interventions may lessen the social communication or language delays characteristic of ASD.

Although the relationship between these two domains is still not thoroughly understood, this study indicates that the traditionally independent provision of communication and motor interventions should be reconsidered. The majority of the included studies were completed relatively recently and indicate improved language outcomes for several different motor-based interventions. Undoubtedly, co-treatment of children with ASD by occupational therapists, physical therapists, and speech-language pathologists in clinical and educational settings is occurring. However, the decision to deliver services in this form is likely influenced by practical concerns such as scheduling, proximity, convenience, and reimbursement. Evidence-based practice also requires such clinical decisions to be based on monitoring and incorporating new and high-quality research [28]. The results of the current study help justify potentially prioritizing the collaboration of clinicians in the provision of therapeutic interventions for children with ASD, even if the identified delays would have historically only supported a certain level of service.

One type of service model for coordination of therapeutic services described by Sylvester, Ogletree, and Lunnen is interprofessional collaborative practice (IPCP), which includes "continuous interaction and knowledge-sharing" [29] between professionals, patients, and stakeholders. The authors argue that IPCP helps advance the everyday outcomes for persons with severe disabilities (not specifically ASD), but they also acknowledge that evidence supporting collaborative processes is limited, even though position statements from both the American Physical Therapy Association and the American Speech-Language-Hearing Association endorse it $[30,31]$. While the findings of the current study do not directly address a specific model of collaborative service delivery, the findings indicate that measuring language outcomes is an important component of gauging the overall success of motor interventions for children with ASD, which, at minimum, necessitates the coordination of physical therapists and speechlanguage pathologists for clinical decision making about specific interventions and reporting progress.

Additionally, incorporating evidence-based practice into clinical decision making requires speech-language patholo- gists to recognize the needs, values, and preferences of individuals and families who are being provided services [28]. Parents of children who go on to be diagnosed with ASD frequently report that delays in language development are their primary concern [32]. However, parents who report concerns about motor skills in children later diagnosed with ASD were first concerned at a younger age than parents who report concerns with communication skills [33]. The same group of parents with motor concerns also sought out services sooner, but only made up a minority (approximately 23\%) of the overall sample. These studies highlight the need for increased awareness of potential red flags related to motor development and ASD for both families and clinicians. The findings of the current study extend that need for increased awareness into the area of intervention. As previously noted, LeBarton and Landa [6] suggested that earlier provision of motor interventions may help alleviate the influence of motor delays on later communication skills in children with ASD. If families were more informed about the potentially facilitative influence of motor interventions on language outcomes, their preferences and values could be more specifically incorporated.

\section{ACKNOWLEDGEMENTS}

Thank you to Daniel Wheeler for his contributions. This research was supported by the NIU College of Health \& Human Sciences, the NIU Division of Research and Innovative Partnerships, and the NIU Center for the Interdisciplinary Study of Language and Literacy.

\section{REFERENCES}

1. American Psychiatric Association. Diagnostic and Statistical Manual of Mental Disorders (DSM-5). 5th ed. Arlington, VA: American Psychiatric Association, 2013.

2. Green D, Charman T, Pickles A, et al. Impairment in movement skills of children with autistic spectrum disorders. Dev Med Child Neurol. 2009;51:311-316.

3. Fournier KA, Hass CJ, Naik SK, et al. Motor coordination in autism spectrum disorders: a synthesis and meta-analysis. J Autism Dev Disord. 2010;40:1227-1240.

4. Hickok G. The architecture of speech production and the role of the phoneme in speech processing. Lang Cogn Process. 2014;29: $2-20$.

5. Goffman L. Dynamic interaction of motor and language factors in normal and disordered development. In: Speech Motor ControlNew developments in basic and applied research. Oxford University Press, https://www.oxfordscholarship.com/view/10.1093/acp rof:oso/9780199235797.001.0001/acprof-9780199235797-chap- 
ter-8 (2010, accessed 12 February 2020).

6. LeBarton ES, Landa RJ. Infant motor skill predicts later expressive language and autism spectrum disorder diagnosis. Infant Behav Dev. 2019;54:37-47.

7. Poon KK, Watson LR, Baranek GT, et al. To what extent do joint attention, imitation, and object play behaviors in infancy predict later communication and intellectual functioning in ASD? J Autism Dev Disord. 2012;42:1064-1074.

8. Stone WL, Yoder PJ. Predicting Spoken Language Level in Children with Autism Spectrum Disorders. Autism. 2001;5:341-361.

9. Mody M, Shui AM, Nowinski LA, et al. Communication Deficits and the Motor System: exploring patterns of associations in autism spectrum disorder (ASD). J Autism Dev Disord. 2017;47:155162.

10. Wang SS-H, Kloth AD, Badura A. The cerebellum, sensitive periods, and autism. Neuron. 2014;83:518-532.

11. Simeonsson RJ, Bailey DB. Evaluating programme impact: levels of certainty. In: Mitchell DM, Brown RI, editors. Early intervention studies for young children with special needs. Boston, MA: Springer US; pp. 280-296.

12. Borgi M, Loliva D, Cerino S, et al. Effectiveness of a Standardized Equine-Assisted Therapy Program for Children with Autism Spectrum Disorder. J Autism Dev Disord. 2016;46:1-9.

13. Ingersoll B. Brief report: effect of a focused imitation intervention on social functioning in children with autism. J Autism Dev Disord. 2012;42:1768-1773.

14. Pfeiffer BA, Koenig K, Kinnealey M, et al. Effectiveness of sensory integration interventions in children with autism spectrum disorders: a Pilot Study. Am J Occup Ther Off Publ Am Occup Ther Assoc. 2011;65:76-85.

15. Woo CC, Donnelly JH, Steinberg-Epstein R, et al. Environmental enrichment as a therapy for autism: a clinical trial replication and extension. Behav Neurosci. 2015;129:412-422.

16. Lau HY. Evaluation of a home-based, transdisciplinary intervention for autism spectrum disorder in Hong Kong. Dissertation, Alliant International University, https://www.ulib.niu.edu:2631/ pqdtglobal/docview/1946176217/ECD932D743FA41EBPQ/1?acc ountid=12846 (2017, accessed 12 February 2020).

17. Caputo G, Ippolito G, Mazzotta M, et al. Effectiveness of a multisystem aquatic therapy for children with autism spectrum disorders. J Autism Dev Disord. 2018;48:1945-1956.

18. Ketcheson L, Hauck J, Ulrich D. The effects of an early motor skill intervention on motor skills, levels of physical activity, and socialization in young children with autism spectrum disorder: a pilot study. Autism Int J Res Pract. 2017;21:481-492.

19. Yoo GE, Kim SJ. Dyadic Drum Playing and Social Skills: implications for rhythm-mediated intervention for children with autism spectrum disorder. J Music Ther. 2018;55:340-375.
20. Ingersoll B, Lalonde K. The impact of object and gesture imitation training on language use in children with autism. J Speech Lang Hear Res JSLHR. 2010;53:1040-1051.

21. Miltenberger CA, Charlop MH. Increasing the athletic group play of children with autism. J Autism Dev Disord. 2014;44:41-54.

22. Preis J, McKenna M. The effects of sensory integration therapy on verbal expression and engagement in children with autism. Int J Ther Rehabil. 2014;21:476-486.

23. Iwanaga R, Honda S, Nakane H, et al. Pilot study: efficacy of sensory integration therapy for Japanese children with high-functioning autism spectrum disorder. Occup Ther Int. 2014;21:4-11.

24. Ingersoll B, Schreibman L. Teaching reciprocal imitation skills to young children with autism using a naturalistic behavioral approach: effects on language, pretend play, and joint attention. J Autism Dev Disord. 2006;36:487-505.

25. Schaaf RC, Benevides T, Mailloux Z, et al. An intervention for sensory difficulties in children with autism: a randomized trial. J Autism Dev Disord. 2014;44:1493-1506.

26. Zanobini M, Solari S. Effectiveness of the program 'acqua mediatrice di comunicazione' (water as a mediator of communication) on social skills, autistic behaviors and aquatic skills in ASD Children. J Autism Dev Disord. 2019;49:4134-4146.

27. Gladfelter A, Johnson E, Odeh C. Parent perceptions of social behaviors associated with autism spectrum disorder are related to motor skills. Commun Disord Q. 2019;1525740119864614.

28. American Speech-Language-Hearing Association (ASHA). Evidence-based practice in communication disorders: an Introduction. American Speech-Language-Hearing Association. Epub ahead of print 2004.

29. Sylvester L, Ogletree BT, Lunnen K. Cotreatment as a vehicle for interprofessional collaborative practice: physical therapists and speech-language pathologists collaborating in the care of children with severe disabilities. Am J Speech Lang Pathol. 2017;26: 206216.

30. American Physical Therapy Association (APTA). Committment to Interprofessional Education and Practice, http://www.apta.org/ Policies/Education/(2019, accessed 12 February 2020).

31. Interprofessional Education/Interprofessional Practice (IPE/IPP). American Speech-Language-Hearing Association, https://www. asha.org/Practice/Interprofessional-Education-Practice/ (accessed 12 February 2020).

32. Yimgang DP, Albury RA, Leppert ML. Do parental concerns predict developmental and behavioral diagnoses in a developmental clinic? Clin Pediatr (Phila). 2017;56:263-267.

33. Guinchat V, Chamak B, Bonniau B, et al. Very early signs of autism reported by parents include many concerns not specific to autism criteria. Res Autism Spectr Disord. 2012;6:589-601. 